\title{
HIV INFECTION AND AIDS IN NSW, 1981 TO 1999
}

\section{Robert Menzies}

Communicable Diseases Surveillance and Control Unit NSW Department of Health

Human Immunodeficiency Virus (HIV) is transmitted via body fluids, through behaviours such as unprotected sexual contact and sharing of intravenous injection equipment, or through transfusion with infected blood products. Initial infection may cause an acute mononucleosis-like illness within several weeks to months, lasting a week or two. Infected people are then usually free of symptoms for many months or years. However, the immune system becomes progressively damaged by the virus, eventually leading to the development of one or more opportunistic infections and cancers. This stage of the illness is described as Acquired Immune Deficiency Syndrome (AIDS). In the absence of effective treatment, the average time from HIV infection to AIDS is eight years, and from AIDS to death is approximately one year. The introduction of effective prophylactic treatments a decade ago increased average survival before AIDS to 10 years. The introduction in 1995 of combination antiretroviral therapy, including protease inhibitors, improved survival dramatically, by approximately 450 per cent. ${ }^{1}$

It is estimated that, at the end of 1997 , over 30 million people had acquired HIV infection worldwide, 11.7 million of whom had died. Approximately 90 per cent of people living with HIV are in sub-Saharan Africa or the developing countries of Asia.

\section{METHODS}

Under the NSW Public Health Act 1991, HIV reference laboratories are required to notify confirmed HIV infection to the NSW Department of Health. Requesting doctors are required to provide those laboratories with the information required for notification, which includes risk exposures, previous tests and clinical status. Medical practitioners and hospitals are required to notify their local public health unit of cases of AIDS. To protect patient's confidentiality, notifications of HIV and AIDS do not include full names or addresses.

The National Centre in HIV Epidemiology and Clinical Research (NCHECR) collates data collected by States and Territories into the National HIV Database and the National AIDS Register. The data presented here on notifications of HIV, AIDS and death with AIDS, are from these sources.

Population data were obtained from National Census estimates for 1999, available through the Health Outcome Information Statistical Toolkit (HOIST), Epidemiology Branch, NSW Department of Health.

Estimates of the number of people living with HIV were calculated as follows. The cumulative number of notifications in NSW and each area health service were adjusted for the estimated number of multiple reports, ${ }^{2}$ AIDS deaths and an estimated range of 10-30 per cent of cases diagnosed with HIV at AIDS diagnosis.

\section{RESULTS}

\section{HIV Notifications}

A total of 11,753 new diagnoses of HIV infection have been notified to the end of 1999 in NSW residents. Of those, between 7,200 and 9,700 were estimated to be living with HIV in 1999 (Table 7). HIV notifications for 1999 (389) were the lowest for any year since testing began in 1985, continuing a downward trend since the peak in 1987 (Table 5). Where information on the cases is available, 95 per cent are male, 70 per cent are aged 25-44 years, 70 per cent reside in Central or South Eastern Sydney Area Health Services, and 90 per cent reside in Sydney.

Where information on risk exposures has been reported, 6,805 (81 per cent) report male to male sexual contact, 255 (three per cent) male to male sex and injecting drug use, and 710 (eight per cent) heterosexual contact. Where further information was available on heterosexual exposure, 90 (35 per cent) were born in a high prevalence country, and 100 (39 per cent) reported sexual contact with a person from a high prevalence country. Injecting drug use without male to male sexual contact was reported

\section{TABLE 5}

PATIENTS NOTIFIED, BY YEAR OF HIV DIAGNOSIS, AIDS DIAGNOSIS, AND DEATH WITH AIDS, NSW, 1981-1999

\begin{tabular}{|c|c|c|c|}
\hline $\begin{array}{l}\text { Year of } \\
\text { diagnosis }\end{array}$ & $\begin{array}{c}\text { HIV } \\
\text { diagnosis }^{1} \\
\text { (Cases } / 100,000 \\
\text { /year) }\end{array}$ & $\begin{array}{c}\text { AIDS } \\
\text { diagnoses }\end{array}$ & $\begin{array}{l}\text { Death with } \\
\text { AIDS } \\
\text { ( } \% \text { of all } \\
\text { AIDS cases) }\end{array}$ \\
\hline 1981 & & 1 & $1(100)$ \\
\hline 1982 & & 1 & $0(0)$ \\
\hline 1983 & & 3 & $1(33)$ \\
\hline 1984 & 199 & 30 & $6(20)$ \\
\hline 1985 & 987 & 90 & $46(51)$ \\
\hline 1986 & 1,110 & 160 & 107 (67) \\
\hline 1987 & 1,635 & 249 & $143(57)$ \\
\hline 1988 & 1,144 & 314 & $138(44)$ \\
\hline 1989 & 982 & 347 & $235(68)$ \\
\hline 1990 & 805 & 421 & $315(75)$ \\
\hline 1991 & 811 & 439 & $336(77)$ \\
\hline 1992 & 710 & 429 & $305(71)$ \\
\hline 1993 & 607 & 468 & $369(79)$ \\
\hline 1994 & 512 & 534 & $410(77)$ \\
\hline 1995 & 541 & 463 & $343(74)$ \\
\hline 1996 & 465 & 350 & $254(73)$ \\
\hline 1997 & 441 & 199 & $110(55)$ \\
\hline 1998 & 414 & 165 & $69(42)$ \\
\hline 1999 & 389 & 90 & $50(56)$ \\
\hline Total & $11,753(11.6)$ & $4,753(4.0)$ & $3,238(68)$ \\
\hline
\end{tabular}


by 364 (four per cent). There have been 31 ( 0.4 per cent) cases of reported mother-to-child transmission.

There has been a strong decreasing trend over the years in the number of people that report male to male sex: 466 (80 per cent where exposure is known) in 1992 to 237 (72 per cent) in 1999. For heterosexual contact there has been little change in the total numbers reported by year, but they have increased as a proportion of total notifications received: 47 (eight per cent) in 1992 to 62 (19 per cent) in 1999. Of those, the number of people reporting being born in a high prevalence country increased: three in 1992 to 20 in 1998, as well as the number of people reporting sexual contact with someone from a high prevalence country: four in 1992 to 23 in 1998.
Data completeness has improved over the years but there is still room for improvement. In 1992 information on risk exposure was available in 82 per cent of notifications, compared to 84 per cent in 1999.

\section{AIDS diagnoses and deaths}

A total of 4,753 AIDS cases have been notified up to 1999, of which 3,238 have died, leaving a total of 1,515 living with AIDS. The first case of AIDS diagnosed in Australia was in Sydney in 1982. One person who died in 1981 was retrospectively diagnosed with AIDS and reported in 1994. ${ }^{3}$ AIDS notifications and deaths peaked in 1994 (534 cases, 410 deaths) and decreased markedly from 1997 onwards. As was the case for HIV notifications, AIDS cases

\section{TABLE 6}

CHARACTERISTICS OF PATIENTS NOTIFIED WITH HIV INFECTION, AIDS AND DEATH WITH AIDS, NSW, 1981-1999

\begin{tabular}{|c|c|c|c|}
\hline Case characteristics & $\begin{array}{l}\text { HIV diagnosis } \\
\text { (\% of total where } \\
\text { data available) }\end{array}$ & $\begin{array}{c}\text { AIDS } \\
\text { (\% of total where } \\
\text { data available) }\end{array}$ & $\begin{array}{l}\text { Death with AIDS } \\
\text { (\% of all AIDS cases) }\end{array}$ \\
\hline \multicolumn{4}{|l|}{ Sex } \\
\hline Male & $10,889(94.6)$ & $4,555(95.8)$ & $3,117(68)$ \\
\hline Female & 599 (5.2) & $187(3.9)$ & $114(61)$ \\
\hline Transgender & $20(0.2)$ & $11(0.2)$ & $7(64)$ \\
\hline \multicolumn{4}{|l|}{ Age group } \\
\hline $0-4$ & $41(0.4)$ & $11(0.2)$ & $5(45)$ \\
\hline $5-14$ & $49(0.4)$ & $10(0.2)$ & $9(90)$ \\
\hline $15-24$ & $1,764(15.1)$ & $170(3.6)$ & $122(72)$ \\
\hline $25-34$ & $4,903(42.0)$ & $1,659(34.9)$ & $1,121(68)$ \\
\hline $35-44$ & $3,268(28.0)$ & $1,786(37.6)$ & $1,204(67)$ \\
\hline $45-54$ & $1,176(10.1)$ & $811(17.1)$ & $562(69)$ \\
\hline $55-64$ & $354(3.0)$ & $233(4.9)$ & $155(67)$ \\
\hline $65+$ & $105(0.9)$ & $73(1.5)$ & $60(82)$ \\
\hline \multicolumn{4}{|l|}{ Risk Exposure } \\
\hline Male-male sex & $6,805(81.0)$ & $3,876(81.5)$ & $2,699(70)$ \\
\hline Male-male sex + IDU & $255(3.0)$ & $174(3.7)$ & $120(69)$ \\
\hline Male-female sex + IDU & $364(4.3)$ & $136(2.9)$ & $75(55)$ \\
\hline Male-female sex (total) & $710(8.4)$ & $218(4.6)$ & $97(44)$ \\
\hline - From high prevalence country & $90(1.1)$ & $41(0.9)$ & $10(24)$ \\
\hline - Sex with person from high prev. & $100(1.2)$ & $24(0.5)$ & $12(50)$ \\
\hline - Sex with bisexual & $47(0.6)$ & $12(0.3)$ & $7(58)$ \\
\hline - Sex with IDU & $47(0.6)$ & $12(0.3)$ & $5(42)$ \\
\hline - Sex with other & $27(0.3)$ & $10(0.2)$ & $8(80)$ \\
\hline - Hetero not further specified & $456(5.4)$ & $119(2.5)$ & $55(46)$ \\
\hline Receipt of blood products & $261(3.1)$ & $155(3.3)$ & $134(86)$ \\
\hline Other & $11(0.1)$ & $17(0.4)$ & $10(59)$ \\
\hline Not stated & 3,317 & 177 & $103(58)$ \\
\hline \multicolumn{4}{|l|}{ AIDS-defining illness ${ }^{1}$} \\
\hline Candidiasis-oesophageal & & $721(15.2)$ & $444(62)$ \\
\hline Cryptococcosis & & $234(4.9)$ & $172(74)$ \\
\hline Cryptosporidiosis & & $164(3.5)$ & $114(70)$ \\
\hline Cytomegalovirus & & $328(6.9)$ & $264(80)$ \\
\hline Herpes simplex & & $172(3.6)$ & $122(71)$ \\
\hline HIV Encephalopathy & & $268(5.6)$ & $174(65)$ \\
\hline HIV Wasting Syndrome & & $456(9.6)$ & $272(60)$ \\
\hline Kaposi's sarcoma & & $772(16.2)$ & $526(68)$ \\
\hline Lymphoma-non-Hodgkin's & & $229(4.8)$ & $177(77)$ \\
\hline Mycobacterial-atypical & & $366(7.7)$ & $266(73)$ \\
\hline Pneumocystis pneumonia & & $1,546(32.5)$ & $1,132(73)$ \\
\hline Toxoplasmosis & & $207(4.4)$ & $164(79)$ \\
\hline Other & & $226(4.8)$ & $138(61)$ \\
\hline
\end{tabular}


TABLE 7

CUMULATIVE NOTIFICATIONS OF HIV DIAGNOSIS, AIDS, DEATH WITH AIDS, AND ESTIMATED NUMBER LIVING WITH HIV INFECTION, BY AREA HEALTH SERVICE OF RESIDENCE AT DIAGNOSIS, NSW (1981-1999)

\begin{tabular}{|c|c|c|c|c|}
\hline Area Health Service & $\begin{array}{c}\text { HIV diagnosis } \\
\text { (annual rate/100,000 } \\
\text { population) }\end{array}$ & $\begin{array}{c}\text { AIDS diagnoses } \\
\text { (annual rate/100,000 } \\
\text { population) }\end{array}$ & $\begin{array}{l}\text { Death with AIDS } \\
\text { (\% of all AIDS cases) }\end{array}$ & $\begin{array}{l}\text { Number living } \\
\text { with HIV }\end{array}$ \\
\hline Central Coast & $97(2.2)$ & $87(1.7)$ & $66(76)$ & $100-140$ \\
\hline Central Sydney & $1,500(19.5)$ & $1,056(11.6)$ & 755 (71) & $1,500-2,100$ \\
\hline Far West & $8(1.0)$ & $3(0.3)$ & $1(33)$ & $7-10$ \\
\hline Greater Murray & $37(0.9)$ & $30(0.6)$ & $16(53)$ & $35-50$ \\
\hline Hunter & $203(2.4)$ & $162(1.6)$ & $113(70)$ & $210-280$ \\
\hline Illawarra & $103(1.9)$ & $93(1.4)$ & $57(61)$ & $110-145$ \\
\hline Macquarie & $16(1.0)$ & $15(0.8)$ & $7(47)$ & $15-20$ \\
\hline Mid North Coast & $85(2.1)$ & $72(1.5)$ & $40(56)$ & $85-115$ \\
\hline Mid West & $53(2.0)$ & $21(0.7)$ & $15(71)$ & $55-80$ \\
\hline New England & $17(0.6)$ & $15(0.4)$ & $7(47)$ & $15-20$ \\
\hline Northern Rivers & $73(1.8)$ & $131(2.7)$ & $75(57)$ & $80-105$ \\
\hline Northern Sydney & $595(4.9)$ & $417(2.9)$ & $314(75)$ & $620-830$ \\
\hline Southern & $20(0.7)$ & $23(0.7)$ & $12(52)$ & $20-30$ \\
\hline South Eastern Sydney & $3,347(27.8)$ & $1,927(13.5)$ & $1,267(66)$ & $3,500-4,700$ \\
\hline South Western Sydney & $297(2.5)$ & $167(1.2)$ & $104(62)$ & $310-420$ \\
\hline Wentworth & $156(3.2)$ & $138(2.4)$ & $102(74)$ & $165-220$ \\
\hline Western Sydney & $316(3.0)$ & $240(1.9)$ & $159(66)$ & $330-450$ \\
\hline Not stated & 4,832 & 156 & $128(82)$ & \\
\hline Total & $11,755(11.6)$ & $4,753(4.0)$ & $3,238(68)$ & $7,200-9,700$ \\
\hline
\end{tabular}

and deaths were predominantly in males (96 per cent), aged 25-44 years (72 per cent), reported male to male sexual contact ( 89 per cent for cases, 90 per cent for deaths), and resided in Central or South Eastern Sydney (65 per cent), where information was available for those variables.

Pneumocystis carinii pneumonia was the most commonly reported AIDS defining illness (33 per cent of cases), followed by Kaposi's sarcoma (16 per cent) and oesophageal candidiasis (15 per cent). Data completeness is very high for AIDS notifications.

\section{DISCUSSION}

These data reflect an HIV-AIDS epidemic that, in comparison with almost any country in the world, has been successfully contained in NSW to date. HIV transmission has been predominantly through male to male sexual contact in NSW. Transmission through injecting drug use is uncommon; the number of notifications that reported injecting drug use is low, and surveys of clients of needle and syringe programs report seroprevalence of less than two per cent in those that do not also report male to male sexual contact. ${ }^{4}$ Transmission through heterosexual contact is also relatively uncommon, and the majority of cases either originated from a high prevalence country, or had sexual contact with a person from a high prevalence country. In particular, confirmed cases of heterosexual transmission, where neither partner was in a high-risk group, were rare.

The figures for AIDS cases and deaths reflect the considerable success of new combination therapies introduced in 1996. The figures for 1999 are incomplete, but after adjustment for reporting delay, a substantial decrease is still apparent. ${ }^{4}$

Prevention measures such as safe sex campaigns targeting men who have sex with men and the sex industry, and needle and syringe programs, have been critically important in containing the epidemic. However, recent increases in notification rates of gonorrhoea, and other sexually transmitted infections in men who have sex with men, ${ }^{5}$ indicate that at-risk behaviours continue and permanent containment of the epidemic is never guaranteed.

\section{REFERENCES}

1. UNAIDS-WHO. Report on the global HIV-AIDS epidemic, June 1998.

2. National Centre in HIV Epidemiology and Clinical Research. Australian HIV Surveillance Report, 1 April 2000; 6 (2): 17.

3. Gerrard JG, McGahan SL, Milliken JS, Mathys JM, Wills EJ. Australia's first case of AIDS? Pneumocystis carinii pneumonia and HIV in 1981. Med J Aust 1994, 160(5): 247250.

4. National Centre in HIV Epidemiology and Clinical Research. HIV-AIDS, Hepatitis C \& Sexually Transmissible Infections in Australia: Annual Surveillance Report 2000. National Centre in HIV Epidemiology and Clinical Research. Sydney: University of NSW, 2000.

5. NSW Department of Health. Year in Review: Communicable Disease Surveillance, 1999. NSW Public Health Bulletin 2000; 11(9-10): 161-168. W 